\title{
Spatio-Temporal Variability of Malaria Infection in Chahbahar County, Iran: Association with the ENSO and Rainfall Variability
}

\section{S. M. J Nazemosadat}

The Atmospheric and Oceanic Research, Shiraz University, Shiraz, Iran center

\section{R Shafiei}

North khorasn University of Medical Sciences

H Ghaedamini

Shiraz University of Medical Sciences

\section{Najjari}

Mashhad University of Medical Sciences

\section{Z Nazemosadat}

Shiraz University of Medical Sciences

Gholamreza Hatam ( $\nabla$ hatamghr@sums.ac.ir)

Shiraz University of Medical Sciences https://orcid.org/0000-0002-7807-4793

\section{Research}

Keywords: malaria, chahbahar, climate, ENSO, SOI

Posted Date: February 26th, 2020

DOI: https://doi.org/10.21203/rs.2.24532/v1

License: (c) (1) This work is licensed under a Creative Commons Attribution 4.0 International License. Read Full License 


\section{Abstract}

Background: Malaria is one of the most widespread communicable diseases in the southeast of Iran particularly in Chahbahar County. Comprehensive understanding of the influence of climate on this disease is a key element for success in the environmental-based malaria elimination programs. After analyzing the spatio-temporal distribution of the disease, the relationships between the infection statistics and some important climate indices particularly the El Niño-Southern Oscillation (ENSO) and rainfall were investigated.

Methods: The malaria statistics collected from various health centers were composited with the corresponding data of Southern Oscillation Index (SOI), ground-based meteorological records and satellite-based rainfall data. Non-parametric Mann-whitely test was applied to detect the significant difference between patient number between El Niño and La Niña and between the adopted wet and dry episodes.

Findings: Patient number from highest to lowest was associated to summer, autumn, spring and winter, respectively. Plasmodium falciparum, Plasmodium vivax and other species were responsible for $22 \%$, $75 \%$ and $3 \%$ of the sickness, respectively. While the outbreak of P. falciparum is in autumn; P. vivax is erupted in summer. When the epidemic statistics were collected from rural rather than urban areas, the effect of climate on the infection statistic was more obvious.

Interpretation: For rural / urban areas, the infection statistics exhibited a significant decline / increase during El Niño episodes. In autumn, spring and winter, patient number has significantly increased / decreased during the dry / wet epochs, respectively. These relationships were, however, reversed during summertime of health indicators are rarely available for every population and period of interest, and available data.

Funding: Shiraz University of Medical Sciences

\section{Introduction}

Malaria is a leading life-threatening mosquito-borne parasitic disease across the globe, accounting for up to 212 million cases and 429000 deaths in 2015(1). In 1924, malaria infection was a serious barrier to the Iran's economic growth since more than one-third of Iran's 13 million population suffered from this infection (2). Malaria control programs initiating from 1945 resulted in eradication/significant suppression of the disease in the northern/southern parts of the country by 1977, respectively(3). In 2010, $90 \%$ of the reported cases in Iran belonged to the southeastern parts of the country (4-8). In spite of the fact that the climate-malaria connection is not yet completely understood, scientific communities know that there is an important balance of temperature, rainfall, and humidity that creates ideal conditions for mosquitoes to breed and transmit malaria parasites(9-13). 
The El Niño-Southern Oscillation (ENSO) is a natural phenomenon described by periodic warming of the ocean surface between the eastern and western parts of the equatorial Pacific Ocean. The warmer water stream essentially oscillates back and forth across this part of the Pacific, much like water in a large container. The El Niño (or warm phase) and La Niña (or cold phase) are the extreme phases of ENSO, which contribute to the predictability of climate anomalies in the global scale. Comprehensive definition of ENSO and its effects on global climate are presented in the web pages of and the Australian Bureau of Meteorology (BOM) and National Oceanic and atmospheric Administration (NOAA) $(14,15)$. Recent studies have shown that ENSO in conjunction with variations in the sea surface temperatures over tropical and extra-tropical water bodies induces a significant impact on precipitation variability and climate change in Iran and West Asia(16-20).

The study area, Chahbahar, is a county located in Sistan- Baluchistan province, in the southeast of Iran with an area of $9739 \mathrm{Km} 2$ and population of 291910 (21). Southern and eastern borders of the county are confined by the Indian Ocean $(115 \mathrm{Km})$ and the Iran-Pakistan border $(131 \mathrm{Km})$, respectively (Fig 1). This specific geographical position is the main reason that makes this area susceptible to malaria (2224).

In this study, we utilized our own methodology for understanding the malaria-climate associations. In contrast to most of the previous studies, we analyzed this association in the seasonal scale and for each of the individual health center. We composited malaria statistics with the Southern Oscillation index (SOI) data that is represented as the ENSO indicator. For the first time, we utilized the satellite-based rainfall data for analyzing the malaria-rainfall relationships. To avoid misleading conclusion, we took the effects of the malaria-elimination policies on these examinations into account.

\section{Data}

Monthly values of temperature, rainfall and relative humidity of Chahbahar station (Fig 2) were obtained from the Iranian meteorological organization for the period 1986-2016 to evaluate climatological behaviors of this region. To distinguish the EI Niño, and La Niña and phases of ENSO, we extracted the corresponding monthly SOI data from the BOM's website (14). Monthly statistics of the number of patients collected in various health centers of Chahbahar were obtained from the regional office of the Ministry of Health and Medical Education in Iran for the period 2001 to 2011.

While the infection statistics were gathered from fourteen health centers, the sole meteorological station was located near the city center on the coast of the Indian Ocean (Fig 2). The difference between the number of health centers and meteorological stations was a big barrier for spatial assessment of the malaria-rainfall relationships. The satellite-based Tropical Rainfall Measuring Mission (TRMM) 3B43 (V7) rainfall data were hence utilized on a calendar month temporal resolution and a $0.25^{\circ}$ by $0.25^{\circ}$ spatial resolution for the period 2001 to 2012(25, 26). The capabilities of the Geographical Information System (GIS) were utilized to convert the TRMM gridded data into the point data for the specified latitudes and longitudes of the health centers. Although the Goddard Earth Sciences Data and Information Services 
Center (GES-DISC) has recommended the application of TRMM data for the Malaria-Modeling Approaches (26), the authors could not find any references for the application of this recommendation, as conducted in the present study.

\section{Methods}

Our preliminary examination revealed that the effects of climate indices on malaria are more obvious if their relationships are investigated in seasonal rather than monthly timescale. The collected monthly data were, hence, averaged into seasonal records so that the January-March, April-June, July-September and October-December periods were adopted as winter, spring, summer and autumn, respectively. The nonparametric Mann-Whitney and Fisher Exact tests were used to investigate the significance of the difference in the weather data or number of patients between various phases of ENSO or between the adopted wet and dry epochs. ${ }^{13,21,27 \text { and } 28}$

\section{Construction of the SOI-climate composites}

Time-series of seasonal SOI (1986-2016) were firstly sorted in ascending order. All years with seasonal SOI equal or less than -5 or equal or greater than +5 were assigned as the El Niño or La Niña events, respectively. Seasonal values of rainfall, temperature and relative humidity in Chahbahar station were matched with the EI Niño and La Niña years to construct the ENSO composites for each variable. The significance of the difference in the mean values of these variables between El Niño and La Niña episodes was then investigated.

\section{Construction of the SOI-malaria composites}

Since malaria data were available for the period 2002-2011, seasonal values of SOI data for this period were firstly sorted. Three years with lowest or highest values of SOI were then considered as the El Niño or La Niña epoch, respectively. The other four years in the middle were assigned as the neutral epochs. The Number of Malaria Infected patients (NMI) during the El Niño and La Niña events denoted by $\mathrm{NMI}_{\mathrm{El}}$ and $\mathrm{NMI}_{\mathrm{La}}$ were then statistically compared for each individual season and health center. Furthermore, the values of $\mathrm{NMI}_{\mathrm{EI}} / \mathrm{NMI}_{\mathrm{La}}$ were used for assessing the measure of the effects of ENSO extreme phases on the malaria statistics. When this ratio is greater/less than unity, the occurrence of the El Niño generally harmonizes with the increase /decrease of the patient number. We also re-examined all the mentioned mathematical procedures when the El Niño, neutral and La Niña epochs were respectively chosen as 4, 2 and 4 years, but the results were generally similar to what is shown here.

\section{Rainfall-malaria composites}

For each individual season or health center, the TRMM rainfall data between 2002 and 2011 were sorted in ascending order. The sorted dataset were then divided into three parts including three years with highest or lowest rainfall and four years in the middle. The significance of the difference in the number of patients was then assessed between the years with highest and lowest rainfall (hereinafter wet and dry 
episodes). The ratio of $\mathrm{P}_{\mathrm{w}} / \mathrm{P}_{\mathrm{d}}$ was also examined for each individual health center to assess the departure of the ratio from unity which demonstrates the effects of rainfall variability on malaria statistics. The mentioned procedures were also re-examined when the wet or dry episodes contain four years, but the results were mostly similar to those depicted in this study.

\section{Results And Discussion}

\section{Climatic features and associations with ENSO}

The mean values of annual rainfall at Chahbahar meteorological station that emphasizes the severity of dryness over the study area is $120 \mathrm{~mm}$ for the period 1986-2016 (Table 1). Winter, spring, summer and autumn rainfalls constitute $53.5 \%, 8 \%, 4.5 \%$ and $34 \%$ of this rainfall, respectively. As indicated, the corresponding seasonal values of temperature or relative humidity were $22 .{ }^{\circ} \mathrm{C}, 29.3^{\circ} \mathrm{C}, 29.2^{\circ} \mathrm{C}$ and $25.1^{\circ} \mathrm{C}$ or $69 \%, 79 \%, 82 \%$ and $70 \%$, respectively. These statistics suggests that, in contrast to rainfall, relative humidity is generally greater for warm rather than cool months of the year.

Autumn/winter rainfall is significantly/remarkably greater for the El Niño as compared with La Niña years. This relationship, however, is reversed for spring and summer, when the mean seasonal rainfall is negligible and deviates from 9.6 to $5.4 \mathrm{~mm}$, respectively. Since rainfall time-series in Chahbahar are affected by frequent near zero and sporadic torrential rain, the presented ENSO-rainfall relationships could change over time for winter, spring and summer, when these relationships are not strongly significant. Compared to El Niño, air temperature tends to be warmer during La Niña episodes from $0.2^{\circ} \mathrm{C}$ to $0.4^{\circ} \mathrm{C}$. Relative humidity, however, is consistently greater during El Niño episodes from about $0.4 \%$ in spring to $7 \%$ in winter.

The impact of ENSO on malaria potentially increases when the difference in the climatic features is significant between El Niño and La Niña, as shown in Table 1. This influence is, hence, more remarkable during autumn, winter, summer and spring, respectively.(21) It is concluded that long-term records of malaria data which are less affected by the disease control programs are needed to establish the ENSOmalaria relationship.

\section{Seasonal distribution of malaria}

Table 2 illustrates the historical records of patient's statistics in twelve health centers during summertime, when total infection is in its highest status. Since the dataset of the other two stations contained some missing data, their statistics are not presented. Similar statistics were also obtained for the other seasons, but due to result briefing, these data are presented in appendix 1 . As indicated, mean values of the number of patients for winter, spring, summer and autumn are correspondingly $267,1501,5159$, and 2885. While the highest records are related to the hot and dry months, the lowest values are linked to winter when rainfall is remarkably higher than the other seasons. These suggest the significant impact of temperature rather than rainfall on the number of patients. 


\section{Infection Types}

P. falciparum, P. vivax and the other types of malaria accounted for $22 \%, 75 \%$, and $3 \%$ of infections, respectively. Fig 3 illustrates the spatial distribution of autumnal $P$. falciparum-infection when the frequency of this type of infection is greater than the other seasons. Similar illustrations related to other seasons are presented in Appendix 2. In spite of the fact that the infection statistics are different from season to season, the spatial patterns of the epidemic are in general agreement, suggesting that the frequency of seasonal infection is firstly the highest over the northeastern and secondly over the southwestern parts of the county (Fig 3 and Appendix 2). According to Fig 4, after autumn, the infection statistics are in the second to fourth ranks during summer, spring and winter, respectively.

Fig 5 is similar to Fig 3 except for $P$. vivax and for summer; when this infection is more acute than the other seasons. Comparing Figs 3 and 5 suggests that, although seasons and infection types are different, the geographical patterns of the infections are almost identical for both Figs. In spite of this coherence, patient number is more than three times for $P$. vivax in Fig 5 as compared with $P$. falciparum in Fig 3 . After summer, the risk of $P$. vivax is, respectively, more severe during autumn, spring and winter (Fig 6). The highest frequencies of $P$. falciparum and $P$. vivax are related to the year 2003 one of the driest year during the study period (Figs 4 and 6). Our examination, however, did not exhibit any exceptional condition in climatic indices for this year. It is noteworthy to mention that the unusually high incidence of malaria is not necessarily driven by unusual weather patterns, and rather, is mediated by other factors such as human behavior, the mosquitos movement patterns, migration and agricultural practices (27).

\section{ENSO phase and malaria}

Table 3 illustrates the autumnal values of the number of patients for the warm and cold phases of the ENSO at Dagres health center as an example. The data are presented for two choices including the options that each of the ENSO phases contains 3 or 4 years. For instance, if three years with lowest or highest values of SOI are adopted as the El Niño or La Niña episodes, the mean values of the number of patients and their associated NMIEI/NMILa are 78.6, 101 and 0.78, respectively. For four years option, the statistics of the years 2004 or 2007 are also included as the El Niño or La Niña year, respectively.

Fig 7 depicts the spatial distribution of the NMIEI/NMILa for autumn, when the difference between NMIEI and NMILa is significant for most of the health centers. Similar Figures were also obtained for the other seasons, but they are presented in appendix 3. (28) We found a statistically significant relationship between El Niño and malaria epidemics in Colombia, Guyana, Peru, and Venezuela (24).

As indicated in Fig 7, in contrast to the northern and particularly northeastern parts of the county, for the urban areas in the southwestern corner of the study area, the ratio of NMIEI/NMILa is greater than unity and deviates from 1.5 to 2.36 . This suggests about $50 \%$ to $136 \%$ increase in the infection statistics of urban areas during El Niño as compared with the corresponding statistics during La Niña events. 
According to this Fig, the effects of the ENSO phases on the number of patients are reversed between eastern and western sides of the county.

\section{Impacts of the malaria elimination policies}

Since ENSO is a global climate phenomenon, it is difficult to accept that the prevalence of the El Niño or La Niña induces an opposite effect on the malaria statistics of the study area, as presented in the previous section. Our close examination revealed that the implementation of malaria eradication policies by Iranian government is probably the main cause of the observed contradiction. While the number of infected people in urban regions has been consistently reduced from 2002 to 2011 , such decline in the number of patients is not found for rural regions

Table 4 delineates the ratio of the number of patients during five years period of 2002-2006 to the corresponding statistics during 2007-2011. As indicated, except for one case (summer in Bahookalat), the ratio is consistently greater than unity. This indicates a considerable reduction in the infection frequency during the 2007-2011, as compared to its preceding five years. The reduction rate is, however, different between health centers and from one season to another. The biggest or smallest ratio values are generally associated to the urban (i.e. Shahri 2 and Shahri 3) or rural areas (i.e. Dagres and Bahookalat), respectively. Statistics in Table 4 prove that the malaria elimination policies are more effective in urban areas as compared to the rural parts of the county. The given results by(23) and (24) generally support these differences.

According to the SOI data, in the 10 years of the study period the autumnal SOI was negative for 4 years and positive for the remaining 6 years. As indicated in Table 3, while the El Niño events had mostly occurred during the first half of the study period, the La Niña years are frequently associated to the second half of this period when the effect of technology for immunity improvement is more obvious. The considered El Niño or La Niña events, therefore, coincide with the periods with low or high effects of technology on the infection statistics, respectively. This means that if the effects of technology on the malaria statistics were removed, El Niño or La Niña events would be generally associated to the decrease or increase in the malaria epidemic as indicated for Sangan, Arabzehi, Dagres and Bahookalat in Fig 7. In other words, the ENSO-malaria relationships are more accurate if these relations are assessed for the rural rather than urban regions.

\section{The ratio of Pw/pd}

Table 5 depicts the mean values of autumnal rainfall for the assigned dry and wet periods at Dagres health center (Fig 2), that is presented as an example. The corresponding numbers of patients (Pw and $\mathrm{Pd}$ ) and the ratio of $\mathrm{pw} / \mathrm{pd}$ are also presented. The three years with lowest or highest rainfall are 2005, 2007 and 2003 or 2011, 2006 and 2004, respectively. Mean values of rainfall for these dry and wet periods, their corresponding number of patients and the ratio of Pw/Pd are presented. These statistics suggest that the autumnal upsurge or decline in the number of patients in Dagres health center is 
statistically associated to the adopted dry or wet events, respectively. The results of the statistical tests remained stationary static when Pw and Pd were four years.

Table 6 is the seasonal values of Pw/Pd for all twelve stations. As indicated, ratios are consistently and significantly less than unity for autumn, winter and spring and greater than 1.0 for summer. This means that the occurrence of wet or dry episodes harmonize is in accordance with the reduction or increase in the number of patients during autumn, winter and spring, respectively. This relationship, however, is reversed for summer. Some direct or indirect malaria-rainfall associations were also reported by other investigators $(27,29)$. Although precipitation provides essential habitat for larvae during the aquatic stages of some infectious diseases, drought can indirectly expand the vector's range while other researchers have also reported some negative relationships between the amount of rainfall and malaria during persistent regional drought.

\section{Conclusion}

In spite of the fact that the patient number for $P$. vivax was more than three times as much as the $P$. falciparum patients, spatial patterns of these diseases were almost identical. The outbreaks of $P$. falciparum or $p$. vivax were observed in autumn and summer, respectively. Relative humidity consistently increased / decreased during El Nino/La Nina. Increase or decrease in the epidemic frequency in rural areas was associated to the La Niña or El Niño episodes. Since this relationship was reversed for urban regions, the study justified that, due to the malaria control programs, the given results for rural areas are more reliable for assessing the malaria-climate connections. The infection rate lower or higher than usual was in general agreement with the proposed wet or dry periods in autumn, spring and winter, respectively. This association was, however, reversed for summer.

\section{Declarations}

Ethics approval and consent to participate: All data can be accessed by vice chancellor of research, Baluchistan University of Medical Sciences and is available. The corresponding author on behalf of all author confirm that the manuscript has not been and will not be published or submitted elsewhere for publication.

Consent for publication: All authors read the article and confirm its submission.

- Competing interests: There are no conflict of interest in present research.

- Funding: The project financially supported by Vice-chancellor for research of Shiraz University of Medical Sciences

\section{Acknowledgment:}

The study was supported by the office of Vice-chancellor for research of Shiraz University of Medical Sciences and also technically supported by Baluchistan University of Medical Sciences. 


\section{References}

1. http://www.who.int/mediacentre/factsheets/fs094/en/.

2. Ziony M. Malaria control in Iran. Public Health Reports. 1950;65(11):351-67.

3. Edrissian G. Malaria in Iran: Past and present situation. Iranian Journal of Parasitology. 2006;1(1):114.

4. Hemami MR, Sari AA, Raisi A, Vatandoost $\mathrm{H}$, Majdzadeh R. Malaria elimination in iran, importance and challenges. International journal of preventive medicine. 2013;4(1).

5. Hatam G. Malaria, control and diagnosis. Iranian Red Crescent Medical Journal. 2010;2010(3):23941.

6. Kazemi B, Najari M, Saneimoghaddam E, Bandehpour M, Seyed N. Detection of Plasmodium parasites in healthy blood donors using polymerase chain reaction. Archives of Iranian Medicine. 2005;8(2):135-8.

7. Rezanezhad H, Menegon M, Sarkari B, Hatam G, Severini C. Characterization of the metacaspase 1 gene in Plasmodium vivax field isolates from southern Iran and Italian imported cases. Acta tropica. 2011;119(1):57-60.

8. Mohammadzadeh T, Hatam G, Kalantari M, Sarkari B, Motazedian MH, Sadjjadi SM, et al. Molecular and microscopic-based characterization of Plasmodium spp. in fars and Hormozgan Provinces, South of Iran. Journal of tropical medicine. 2014;2014.

9. Krefis AC, Schwarz NG, Krüger A, Fobil J, Nkrumah B, Acquah S, et al. Modeling the relationship between precipitation and malaria incidence in children from a holoendemic area in Ghana. The American journal of tropical medicine and hygiene. 2011;84(2):285-91.

10. Abiodun GJ, Maharaj R, Witbooi P, Okosun KO. Modelling the influence of temperature and rainfall on the population dynamics of Anopheles arabiensis. Malaria journal. 2016;15(1):364.

11. Sena L, Deressa W, Ali A. Correlation of climate variability and malaria: a retrospective comparative study, Southwest Ethiopia. Ethiopian journal of health sciences. 2015;25(2):129-38.

12. Soverow JE, Wellenius GA, Fisman DN, Mittleman MA. Infectious disease in a warming world: how weather influenced West Nile virus in the United States (2001-2005). Environmental health perspectives. 2009;117(7):1049.

13. Parham PE, Pople D, Christiansen-Jucht C, Lindsay S, Hinsley W, Michael E. Modeling the role of environmental variables on the population dynamics of the malaria vector Anopheles gambiae sensu stricto. Malaria Journal. 2012;11(1):271.

14. http://www.bom.gov.au/climate/enso/history/In-2010-12/ENSO-what.shtml [Internet]. Available from: http://www.bom.gov.au/climate/enso/history/ln-2010-12/ENSO-what.shtml.

15. http://oceanservice.noaa.gov/facts/ninonina.html [Internet]. Available from: http://oceanservice.noaa.gov/facts/ninonina.html.

16. Nazemosadat $\mathrm{M}$, Cordery I. On the relationships between ENSO and autumn rainfall in Iran. International Journal of Climatology. 2000;20(1):47-61. 
17. Nazemosadat $\mathrm{M}$, Ghaedamini H. On the relationships between the Madden-Julian oscillation and precipitation variability in southern Iran and the Arabian Peninsula: Atmospheric circulation analysis. Journal of Climate. 2010;23(4):887-904.

18. Nazemosadat M, Ghasemi A. Quantifying the ENSO-related shifts in the intensity and probability of drought and wet periods in Iran. Journal of Climate. 2004;17(20):4005-18.

19. Nazemosadat M, Samani N, Barry D. ENSO forcing on climate change in Iran: Precipitation analysis. Iranian Journal of Science and Technology, Transaction B: Engineering. 2006;30(ECOL-ARTICLE2007-006):555-65.

20. Nazemosadat MJ, Shahgholian K. Heavy precipitation in the southwest of Iran: association with the Madden-Julian Oscillation and synoptic scale analysis. Climate Dynamics. 2017:1-19.

21. Zubair L, Galappaththy GN, Yang H, Chandimala J, Yahiya Z, Amerasinghe P, et al. Epochal changes in the association between malaria epidemics and El Niño in Sri Lanka. Malaria journal. 2008;7(1):140.

22. Halimi MZ-C, Z and Jafari-Modrek, M. Impact of El Niño Southern Oscillation (ENSO) on Annual Malaria Occurrence in Iran. Iranian Journal of Health and Environment. 2016;9 (3):369-83.

23. Fekri S, Vatandoost $H$, Daryanavard A, Shahi M, Safari R, Raeisi A, et al. Malaria situation in an endemic area, southeastern iran. Journal of arthropod-borne diseases. 2014;8(1):82.

24. Hanafi-Bojd A, Vatandoost H, Philip E, Stepanova E, Abdi A, Safari R, et al. Malaria situation analysis and stratification in bandar abbas county, southern Iran, 2004-2008. Journal of Arthropod-Borne Diseases. 2010;4(1):31.

25. https://trmm.gsfc.nasa.gov/ [Internet]. Available from: https://trmm.gsfc.nasa.gov/.

26. https://pmm.nasa.gov/data-access/downloads/trmm [Internet]. Available from: https://pmm.nasa.gov/data-access/downloads/trmm.

27. Wardrop NA, Barnett AG, Atkinson J-A, Clements AC. Plasmodium vivax malaria incidence over time and its association with temperature and rainfall in four counties of Yunnan Province, China. Malaria journal. 2013;12(1):452.

28. Gagnon AS, Smoyer-Tomic KE, Bush AB. The El Nino southern oscillation and malaria epidemics in South America. International Journal of Biometeorology. 2002;46(2):81-9.

29. Odongo-Aginya E, Ssegwanyi G, Kategere P, Vuzi P. Relationship between malaria infection intensity and rainfall pattern in Entebbe peninsula, Uganda. African health sciences. 2005;5(3):238-45.

\section{Figures}




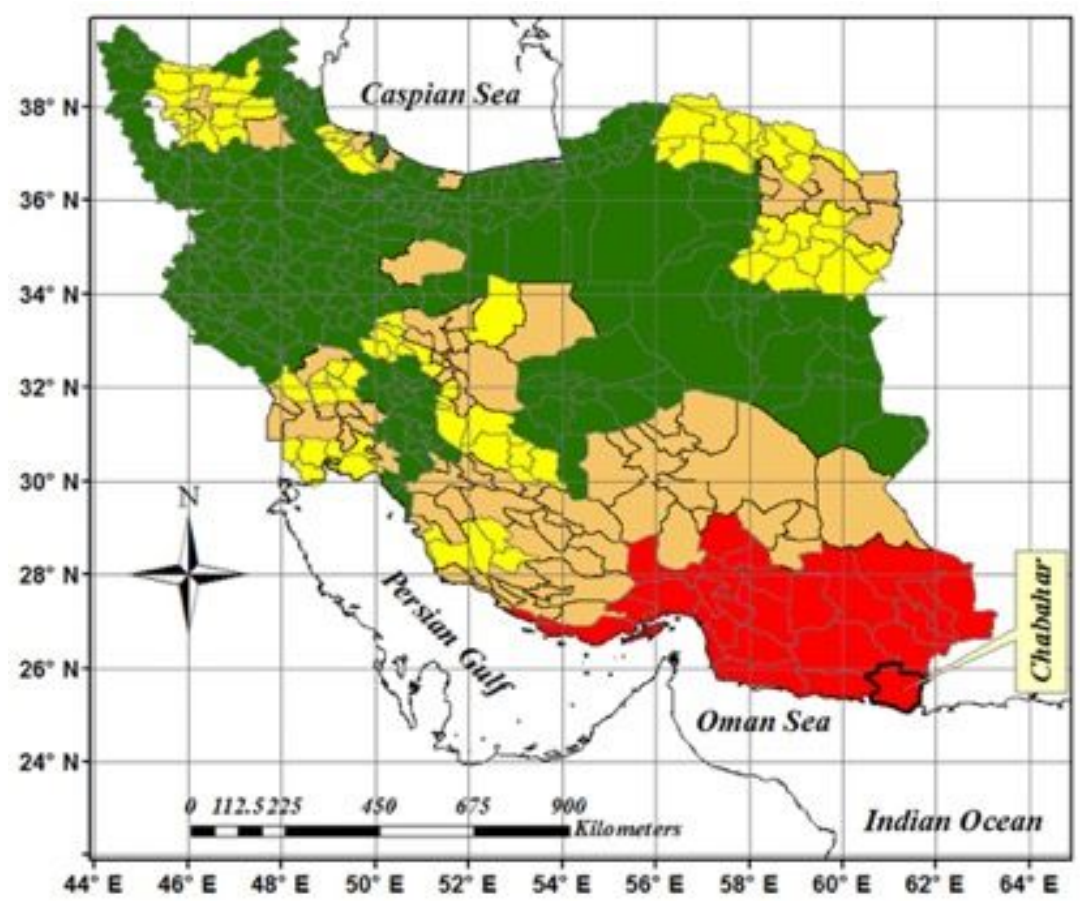

Figure 1

Malaria risk map in Iran according to the districts classification. Chahbahar is located in the southeast of the country on the coast of Oman Sea denoted by solid black line. (Red) with Malaria transmission; (Orange) without transmission, but high risk; (Yellow) without transmission and low risk; (Green) free malaria districts. This Fig is the enhanced version of the Fig obtained in Hemami et al. (2013).

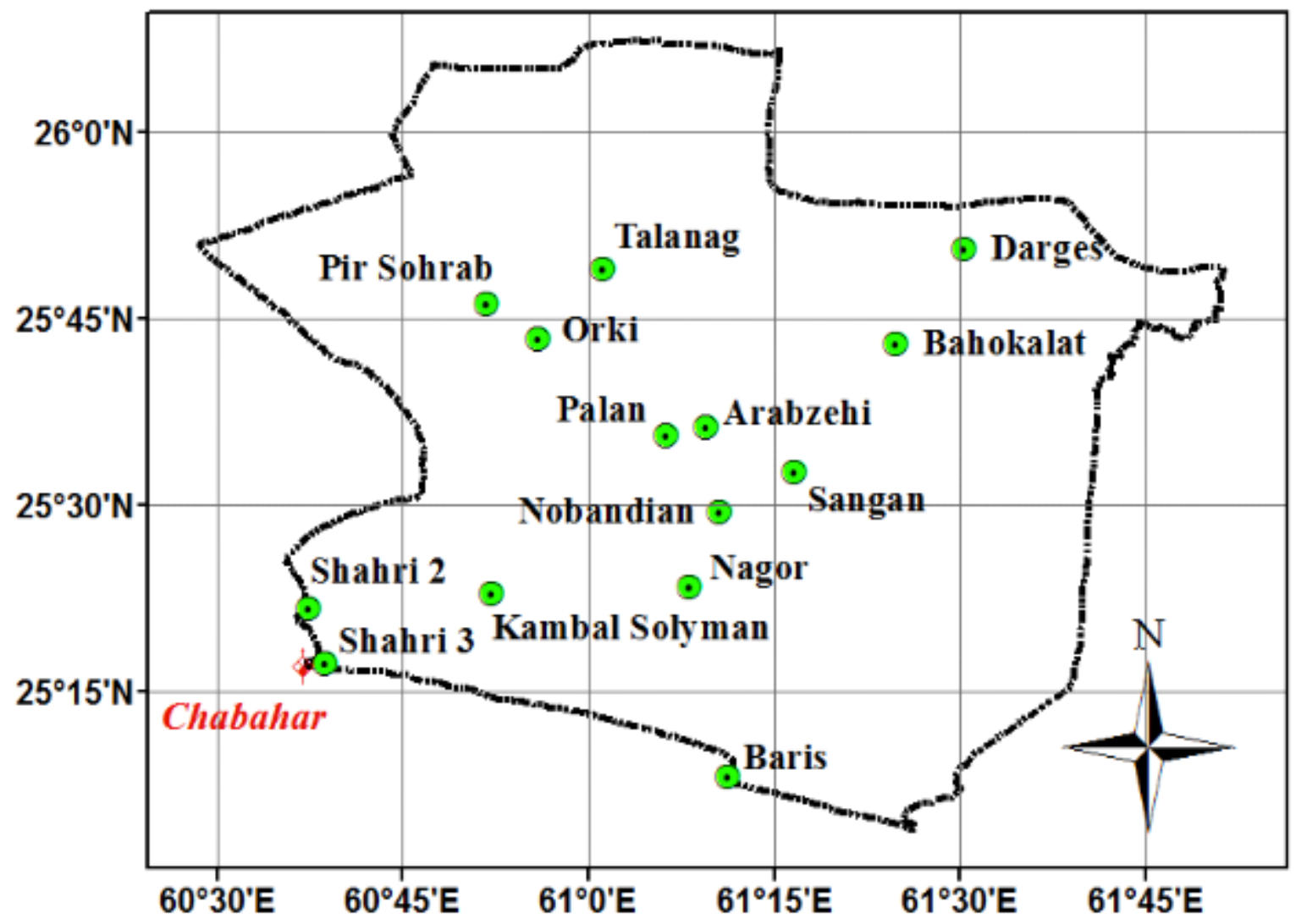


Figure 2

The spatial distribution of the health centers around Chahbahar. The position of the meteorological station is denoted by "chahbahar" in red color.

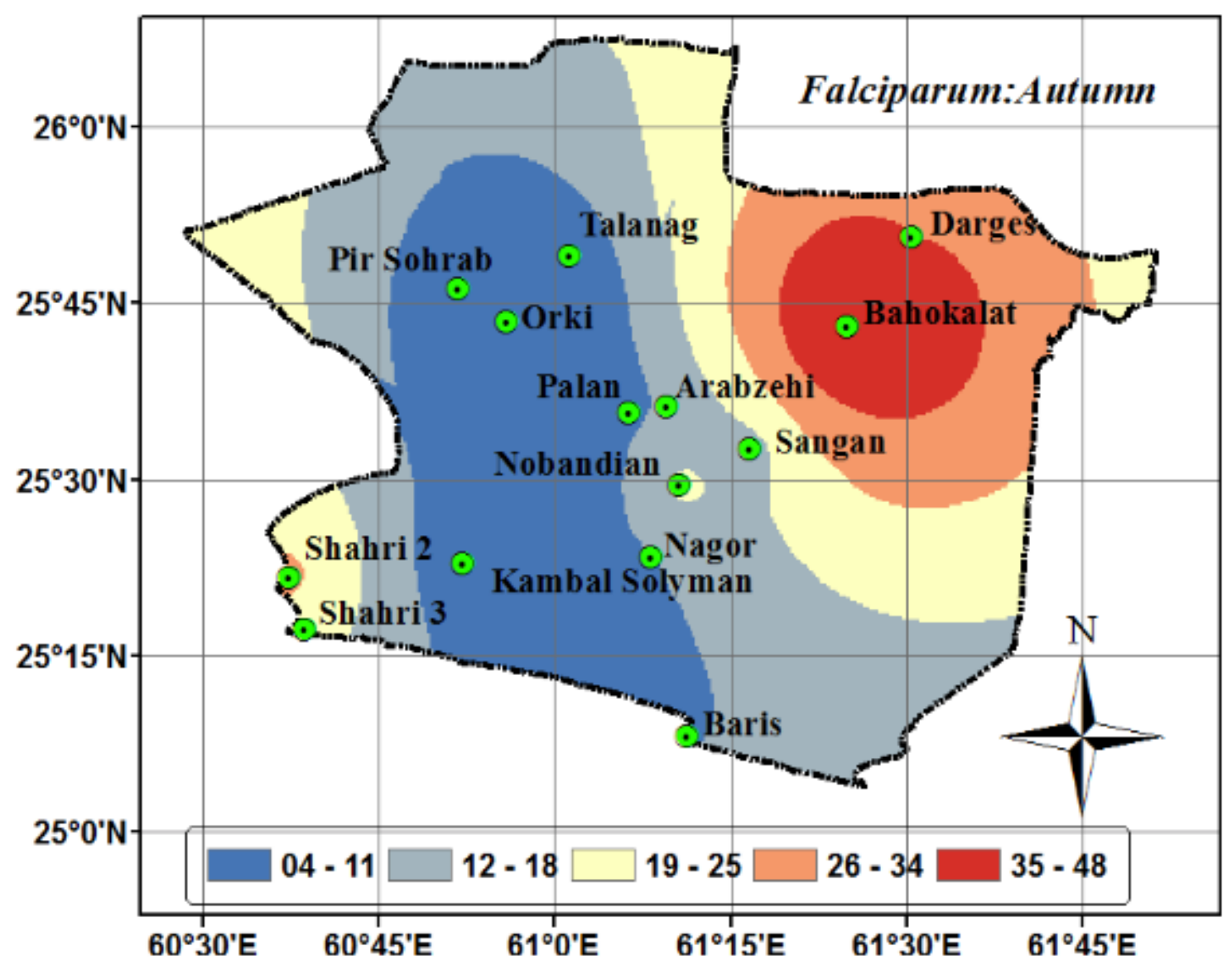

Figure 3

Spatial distribution of P. falciparum during autumn; when the frequency of the infected people is higher than the other seasons 


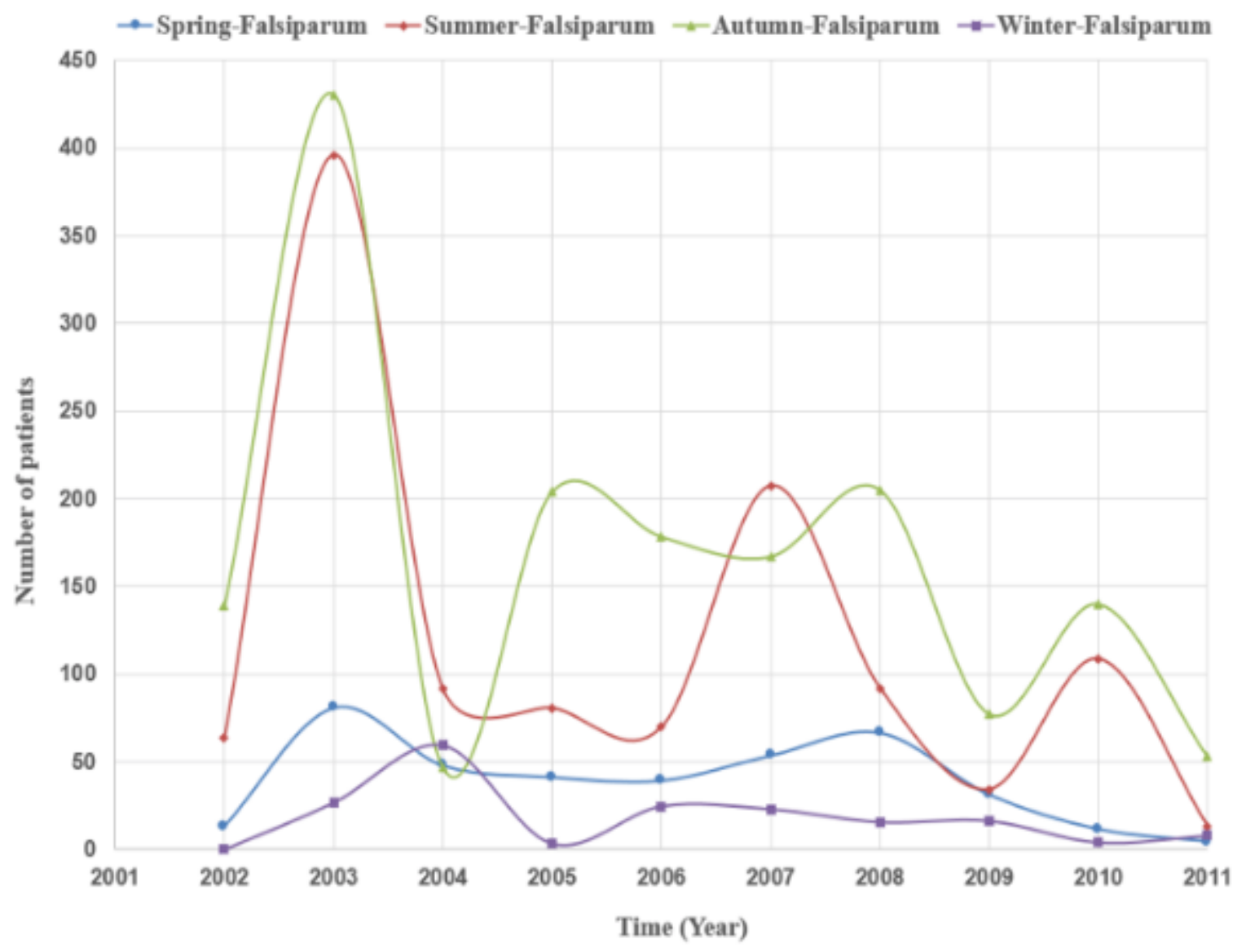

Figure 4

Seasonal variations of P. falciparum for for the study period 


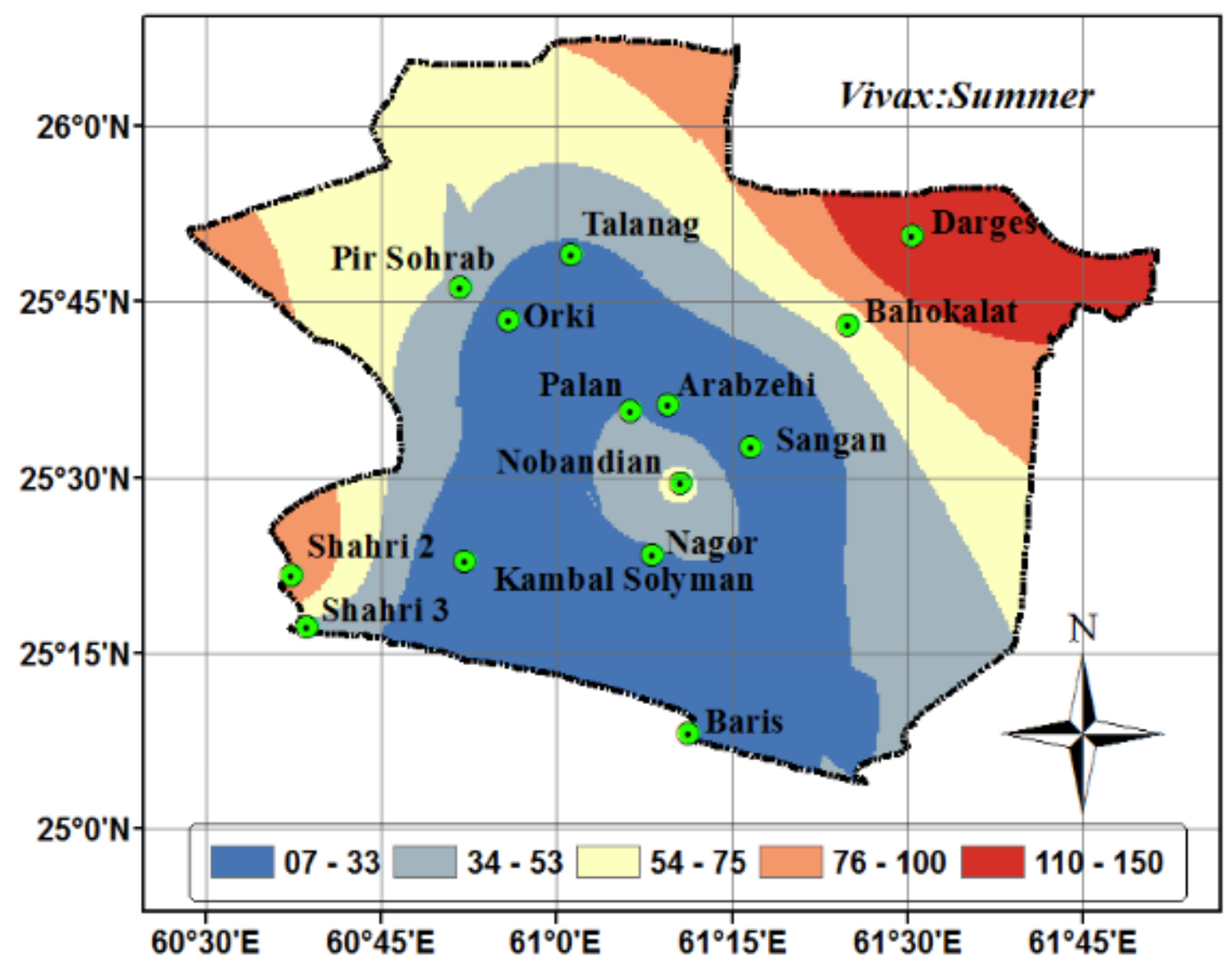

Figure 5

Spatial distribution of P. vivax during summer; when the frequency of this infection is greater than the other seasons 


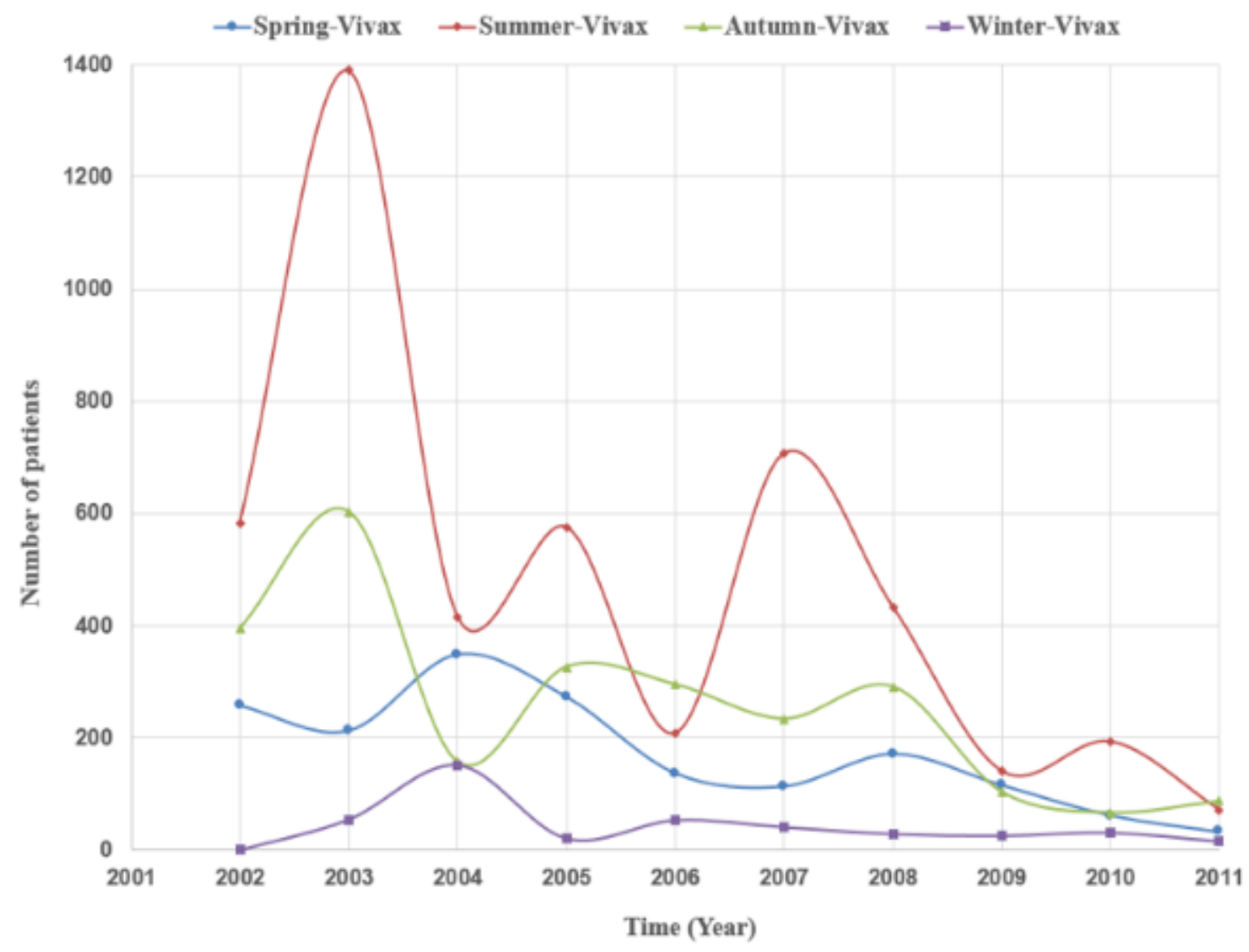

Figure 6

Seasonal variations of P. vivax for for the study period

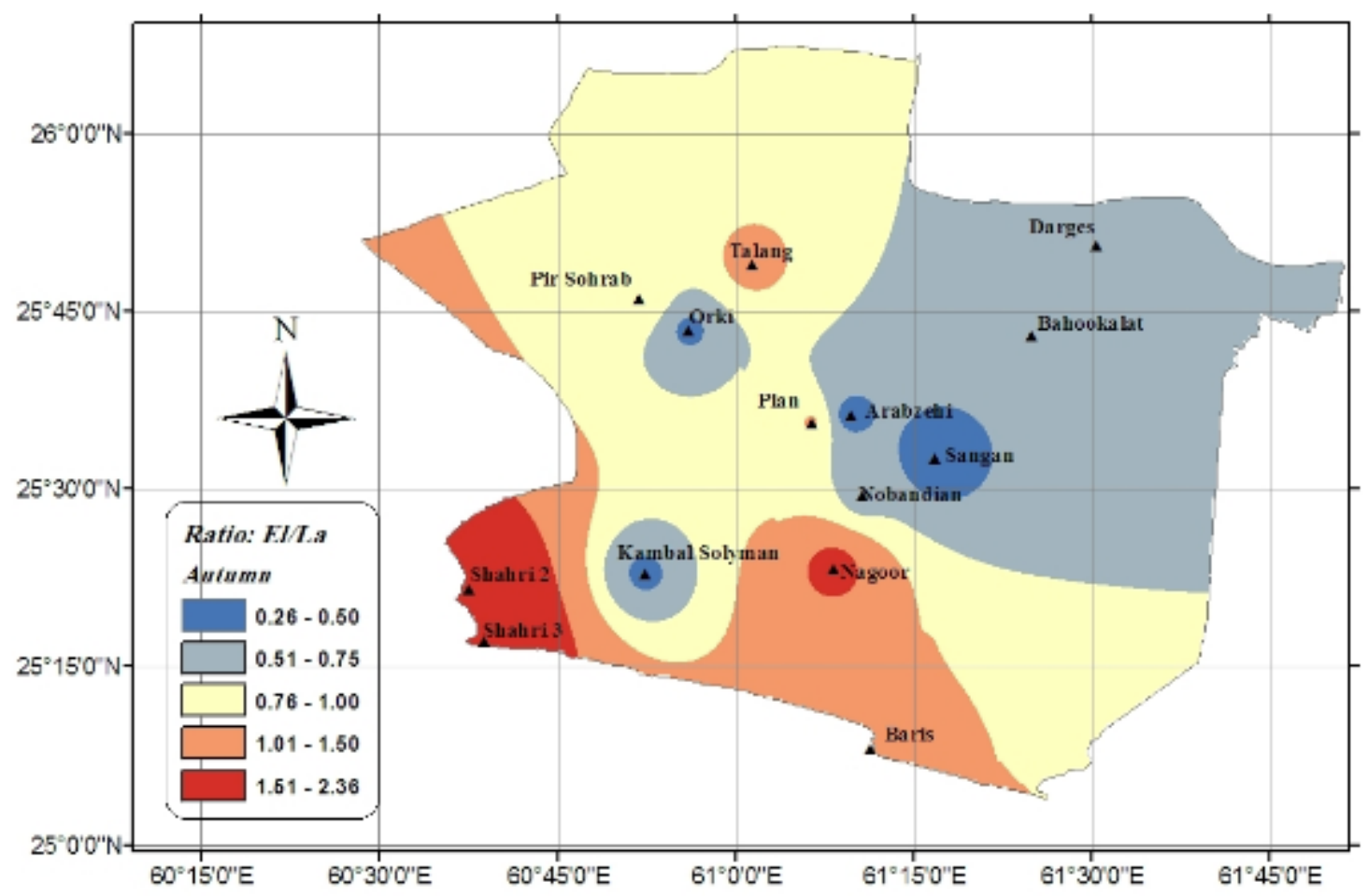


Figure 7

Spatial distribution of the NMIEI / NMILa for autumn. 